\title{
PREOCUPAÇÕES PÚBLICAS, AÇÕES PRIVADAS: UMA TIPOLOGIA DAS FORMAS DE CONSUMO ENGAJADO.
}

\author{
PUBLIC CONCERNS, PRIVATE ACTIONS: \\ A TYPOLOGY OF FORMS OF CONSUMPTION ENGAGED.
}

Jéssica Maria Rosa Lucion*

DEBUISSON-QUELLER, Sophie. La consommation engagée. Paris: Sciences Po., Les Presses, 2012. ISBN: 9782724687415.

A emergência da Nova Sociologia Econômica (NSE) abriu caminho para a retomada da compreensão do mercado enquanto construção social, neste sentido, a ação econômica está imbricada em um emaranhado de valores, normas e relações sociais dos quais o consumo é uma expressão. Compondo o bojo dessas ações, considera-se que aspectos sociais, éticos e políticos estão inscritos no ato da compra ou da sua abdicação, para Micheletti (2003) os indivíduos são political consumers (consumidores politizados) quando questionam se as "políticas dos produtos" estão em consonância com sua filosofia de vida e ideologia política, neste sentido, se expressam através do consumer activism (consumo ativista). No consumer activism os indivíduos expressariam sua cidadania através de ações não institucionais, suas escolhas e julgamentos sobre os produtos apontam para o desejo de mudança das práticas do mercado institucional, assim a esfera econômica passa a ser encarada como arena política e as mercadorias submersas num complexo normativo e valorativo (Idem).

Compartilhando do entendimento de Micheletti (2003), Debuisson-Queller (2012) compreende que o consumo é espaço propício para práticas de contestação social o que denomina de consumo engajado: a vontade dos indivíduos de suas filosofias e posições politicas através do consumo. Le consommation engagée (2012) é dedicado às leituras possíveis desse fenômeno e aos impactos so-

\footnotetext{
* Bacharel em Ciências Sociais, membro discente do Laboratório de Investigação Sociológica (LabIS) da Universidade Federal de Santa Maria e Mestranda no Programa de Pós-Graduação em Ciências Sociais da Universidade Federal de Santa Maria (UFSM), Santa Maria, RS, Brasil; E-mail: jessicalucion@hotmail.com
} 
ciais e econômicos que pode causar. Neste sentido, a obra se reporta as diferentes formas de consumo engajado, suas raízes e dimensões contemporâneas, buscando construir uma tipologia das formas de engajamento social via consumo. Para a autora, a responsabilidade individual designada por um problema coletivo é o traço comum entre várias formas de consumo engajado, por isso considera-o enquanto ação coletiva individualizada.

No início da obra, Debuisson-Queller (2012) se volta para a reconstrução da história do movimento dos consumidores dando atenção aos repertórios de ação emergentes desde o início do século XIX, principalmente as experiências reportadas a manifestações em torno da justiça social como pode ser observado no exemplo dos Estados Unidos onde, no início do século XIX, é possível perceber que a mobilização antiescravagista volta-se para o consumo incentivando a rejeição de mercadorias confeccionadas por escravos e a compra daquelas originadas do trabalho livre. Também em meados do século XIX, tem-se a formação de cooperativas de produção, que comercializavam seus produtos a preços acessíveis as famílias carentes, e, no final do século XIX, a emergência de grupos organizados de consumidores na América do Norte e Europa que traz à tona um projeto de moralização das práticas produtivas que volta-se para o incentivo a aquisição de produtos cujas condições de fabricação respeitem a dignidade humana.

Devido as suas raízes históricas, o consumo engajado não é considerado uma novidade, porém, ganhará contornos mais visíveis a partir do século XX, principalmente através das ações de boicotel mobilizadas pelas classes médias nos países anglo-saxões e na França que intencionavam despertar a responsabilização dos consumidores acerca das condições de produção e os direitos sociais dos trabalhadores. As cooperativas de produção e os sindicatos incitavam a mobilização acionando os consumidores como aliados na luta dos trabalhadores, assim os boicotes aparecem como estratégia para complementar as atividades sindicais.

Pouco tempo depois, as mobilizações em torno da justiça social saem de cena dando lugar às apreensões individuais, as emergentes associações voltam-se para a defesa dos direitos dos consumidores

${ }^{1} \mathrm{O}$ boicote é a negação de consumir um produto ou serviço como forma de protesto, o buycott, ao contrário, é a preferência por comprar produtos ou utilizar serviços como forma de protesto. 
buscando exercer pressão sobre as empresas para que cumpram as legislações em vigor. Nesse período visualiza-se a criação de diversas estruturas voltadas para estes objetivos, como a Consumer Research, criada em 1927, que tinha por objetivo testar a qualidade dos produtos preconizando, assim, o "consumidor expert e vigilante" que pauta pelo produto de qualidade como um de seus direitos. Essa espécie de institucionalização da voz dos consumidores afasta o consumo da arena das manifestações sociais para coloca-lo enquanto dispositivo de regulação dos mercados, para Debuisson-Queller (2012) essa situação inverte em favor do engajamento social dos consumidores a partir da década de 1990, mobilizada, principalmente, pelo refloramento dos movimentos pela justiça social e pelo movimento ecológico.

As preocupações em torno da questão ambiental se traduzem, essencialmente, em ações de buycott orientadas por selos ecológicos presentes nas embalagens dos produtos indicando que tais mercadorias integram novos critérios éticos. Os primeiros selos ecológicos surgiram na Alemanha no final de década de 1970 sendo os selos FSC (Forest Stewardhip Council) e MSC (Marine Stewardship Council) dois principais exemplos de reconhecimento mundial. Para Debuisson-Queller (2012) a compra de produtos certificados aponta para certa pressão dos consumidores sobre os mercados. Um exemplo é a redefinição dos problemas públicos via práticas de rotulagem ecológica evidente no caso da agricultura orgânica. Como se propõem a não utilizar agroquímicos, organismos geneticamente modificados (OGM) e a respeitar os direitos humanos primando por condições justas de trabalho, os alimentos oriundos de sistemas produtivos orgânicos podem ser considerados singulares e uma das formas de garantir esta singularização é através do uso de selos: eles indicam que estes produtos têm repercussões positivas para o meio ambiente, orientando assim os consumidores que permeiam suas escolhas por estas preocupações².

A opção por produtos certificados pode ser considerada uma ação coletiva individualizada, na medida em que os indivíduos assu-

\footnotetext{
${ }^{2}$ É importante mencionar que Debuisson-Queller (2012) aponta que a maior parte dos consumidores de produtos orgânicos os adquire por preocupações individuais (como melhor qualidade de vida, de saúde) e não por razões éticas voltadas para a proteção ambiental. Mesmo assim, o movimento ecológico continua incentivando esta forma de consumo, pois, mesmo orientada para apreensões individuais, incentiva causas mais ampla $\backslash$ relacionadas às questões ecológicas.
} 
mem responsabilidades sociais através da vida cotidiana individual, as iniciativas em torno do Fair Trade (comércio justo) também caminham neste sentido. O comércio justo pode ser definido como um sistema econômico de solidariedade entre consumidores dos países do hemisfério norte e pequenos produtores do sul onde projetos em torno da justiça social animam as "trocas justas" que tem como principal objetivo reintegrar aos circuitos de mercado produtores marginalizados assegurando-os remuneração justa e acesso ao desenvolvimento econômico. Neste sentido, engloba algumas garantias: que o cálculo dos preços levará em conta as condições de vida e de trabalho dos produtores, que as relações econômicas e sociais serão estabelecidas a longo prazo, que as cooperativas e associações de produtores serão gestionadas de forma transparente e democrática e que os sistemas produtivos ecológicos serão priorizados.

Essas relações entre indivíduos de diferentes países permitiram, a partir dos anos 1990, a formalização dos princípios do comércio justo e o reconhecimento de seus atores, bem como a formação de organizações representativas. No mesmo período, delineiam-se as primeiras experiências de certificação do comércio justo que sofreram muitas críticas, visto ser encaradas como mecanismo de mercantilização. As partes finais da obra em tela são dedicadas às ações de resistência às estratégias de mercantilização, mais especificamente ao consumo de massa cuja crítica foi marcada pela organização de diversas ações de boicote em todo o mundo, principalmente em relação às questões alimentares, como o movimento organizado na Suécia na década de 1970, em torno dos altos preços do leite e da carne as manifestações em torno qualidade dos produtos e da segurança alimentar que ganham corpo no França na década de 1980. Para Debuisson-Queller (2012) a resistência ao consumo de massa não se esgota em ações organizadas de boicote, por vezes está inscrita nas experiências cotidianas dos consumidores quando buscam evitar as "armadilhas" postas pelo mercado esquivando-se das propagandas de marketing, por exemplo.

De maneira geral, essas ações se apoiam no engajamento dos consumidores em redes de comércio alternativas e na sua mobilização para ações de protesto. A resistência à cultura de massa tam- 
bém é mobilizada por campanhas antipublicitárias conhecidas como culture jamming que desde os anos 1980 aponta para o fomento de práticas não consumistas, por essa razão, apontado como expressão de contra cultura. Seu alvo é o marketing realizado por grandes empresas que buscam introduzir seus produtos no mercado por via unilateral, assim o culture jamming incentiva os participantes a consumirem produtores alternativos ecológicos e socialmente justos.

A análise de Debuisson-Queller (2012) também é composta pelos movimentos de encolhimento da economia e da simplicidade que remetem aos estilos de vida tradicionais representados atualmente pelos Mormons, Amish, que recusam as "tentações" da sociedade de consumo, os Menonitas e os Quakers. A ênfase na simplicidade consiste na redução do tempo de trabalho, que reduz a renda e, por consequência, o consumo. Assim como outras formas de mobilização dos consumidores, esses movimentos não apontam para ações coletivas com repercussão política, ao contrário de alguns movimentos pelo encolhimento da economia que França, por exemplo, teriam alçado certo engajamento político.

$\mathrm{Na}$ esteira dos movimentos de "esquiva" às práticas institucionais de mercado, ainda deve-se considerar o comércio alternativo que se proliferou a partir dos anos 1990. Segundo Debuisson-Queller (2012), os consumidores o adotaram por uma pluralidade de causas como a compra de produtos considerados saudáveis, a defesa do meio ambiente, a valorização da agricultura familiar e dos produtos regionais, e o desenvolvimento da economia local, neste sentido, os consumidores podem ser mobilizados por movimentos que extrapolam a esfera do consumo, o que torna estas redes um potencial espaço de "recrutamento" de militantes para causas mais amplas, como a justiça social já mencionada.

A autora parte da ideia de que os sistemas de comércio alternativos representam nova forma de governança dos consumidores na organização econômica. Esses sistemas podem ser identificados sob dois formatos principais, o primeiro deles é o da economia solidária formada por cooperativas e associações de produtores onde os valores humanos tornam-se mais importantes que o lucro, portanto 
o foco das ações está no desenvolvimento local, na inserção econômica dos pequenos produtores e na luta contra a exclusão social. Os jardins de inserção e os sistemas de trocas locais são as duas principais experiências de economia solidária identificadas na obra em tela. Quanto ao primeiro, seu principal objetivo é a reinserção econômica dos indivíduos excluídos do mercado, uma de suas atividades é o recrutamento de consumidores mobilizados contra a exclusão social. Nestes espaços prioriza-se a agricultura ecológica, portanto é também local de sensibilização diante das problemáticas agrícolas e da promoção de sistemas produtivos ecológicos, o que aponta para preocupações dos consumidores com questões ambientais.

Os sistemas de trocas locais, por outro lado, funcionam com a criação de moedas locais que circulam nos espaços de comércio alternativo onde as relações de oferta e demanda são construídas através do capital próprio e do contato direto entre produtores e consumidores. A organização local de moedas se insere em objetivos econômicos, como a possibilidade de controlar a distribuição dos recursos tornando-a mais justa, e também sociais, a partir da criação de comunidades locais calcadas no princípio da solidariedade. $\mathrm{O}$ segundo sistema de comércio alternativo é baseado na troca direta entre produtores e consumidores e compõe o movimento de reconexão que se insurge contra o contexto mundial de transformações agrícolas do pós-segunda guerra que romperam com as ligações locais de produção e consumo, modificaram os hábitos alimentares com a introdução de alimentos industrializados e fizeram emergir a insegurança alimentar. Diante disso, os consumidores procuram diretamente os agricultores para adquirir produtos seguros porque não confiam mais no mercado institucional.

Em tom de conclusão, Debuisson-Queller (2012) empreende uma tipologia das práticas de consumo engajado que num primeiro momento diferencia as ações individuais das coletivas e, posteriormente, separa as ações ligadas ao ato de compra daquelas relacionadas a um estilo de vida, que envolvem um compromisso. Neste sentido, o boicote e o buycott, orientados principalmente pela certificação de produtos, apontariam para ações individuais ligadas ao ato 
de compra, enquanto a opção por redes alternativas indicaria uma ação coletiva ligada aos atos de compra. As práticas de resistência ao consumo, como a adoção de modos de vida simples ou de contra cultura, bem como as ações coletivas de consumidores, como ações antipublicitárias, petições públicas ou movimentos de encolhimento do mercado, representam ações de consumo relacionadas a uma filosofia de vida ou ideologia política, sendo estas de contestação individual e política, respectivamente.

A autora conclui que essas ações apontam para um novo formato de engajamento coletivo. No entanto, ao mesmo tempo em que se posicionam contra o mercado, incentivando novas economias, contribuem, paradoxalmente, para a expansão do mercado institucional que cria novos produtos, dispositivos, exigências e propriedades comerciais, neste sentido, incorpora os valores emergentes e ao invés de desestabilizar-se acaba reforçado. No entanto, Debuisson-Queller (2012) aponta que isso não esgota a diversidade do consumo engajado bem como sua possibilidade de protesto contra o mercado. A variedade de repertórios permite redesenhar a realidade do consumo como envolto em práticas que se estruturam entre as escolhas individuais e as oportunidades de ação oferecidas pelos grupos ativistas.

\section{REFERÊNCIAS:}

MICHELETTI, M. Political virtue and shopping: Individuals, consumerism, and collective action. New York: Palgrave Macmillan, 2003.

Recebida em: 15/05/2015

Aprovada em: 14/06/2015 